\title{
IMPLANTAÇÃO DE PROGRAMA DE PREPARAÇÃO PARA APOSENTADORIA NO CORPO DE BOMBEIROS MILITAR DE SERGIPE
}

Rosângela Santos Gomes ${ }^{1}$

\begin{abstract}
RESUMO
O processo de aposentadoria constitui uma vivência singular na vida de cada indivíduo. Muitos experienciam sentimentos de ambivalência, uma mistura de sensações angustiantes envolvendo prazer e desprazer, dificultando 0 indivíduo no enfrentamento da nova etapa. Este estudo tem por objetivo descrever sobre os fatores biopsicossociais que influenciam de forma negativa o processo de aposentadoria e propor a implantação de um Programa de Preparação de Aposentadoria (PPA) no Corpo de Bombeiros Militar de Sergipe, denominado "Reformação". Para a implantação do projeto serão selecionados profissionais que faltam dois anos para a aposentadoria, o programa ocorrerá no período de 4 meses, com encontros quinzenais. A estratégia é trabalhar de forma interdisciplinar utilizando técnicas de avaliação psicológica, aplicação de questionário, palestra, dinâmica grupal, debates, reflexões, depoimentos, com a finalidade de minimizar os sentimentos ambivalentes que surgem durante 0 processo de aposentadoria, proporcionando ao militar reorientação e ajudandoo no enfrentamento desta nova fase com melhor qualidade de vida.
\end{abstract}

Palavras-chave: Aposentadoria; Militar; Programa; Reformação.

$1^{\circ}$ Tenente do Corpo de Bombeiro Militar do Estado de Sergipe, Bacharel em Segurança Pública pela Academia da Policial Militar do Cabo Branco, graduada em Psicologia pela Faculdade Pio Décimo, especialista em Psicologia Organizacional e do Trabalho, especialista em Avaliação Psicológica. Email: rosangelagomespsi@gmail.com 


\title{
PROPOSAL FOR THE IMPLEMENTATION OF A RETIREMNT PREPARATION PROGRAM IN THE MILITARY FIRE BRIGADE OF SERGIPE
}

\begin{abstract}
The retirement process is a unique experience in each individual's life. Many experience feelings of ambivalence, a mixture of distressing sensations involving pleasure and displeasure, making it difficult for the individual to face the new stage. This study aims to describe the biopsychosocial factors that negatively influence the retirement process and propose the implementation of a Retirement Preparation Program (PPA) in the Sergipe Military Fire Department, called "Reformação". For the implementation of the project will be selected professionals who are two years before retirement, the program will take place in a period of 4 months, with biweekly meetings. The strategy is to work in an interdisciplinary way using psychological assessment techniques, questionnaire application, lecture, group dynamics, debates, reflections, testimonies, in order to minimize the ambivalent feelings that arise during the retirement process, providing the military with reorientation by helping them 0 face this new phase with a better quality of life.
\end{abstract}

Keywords: Retirement; Military; Program, Reformação. 


\section{INTRODUÇÃO}

O aumento significativo da população idosa no país tem mobilizado pesquisadores, gestores públicos e privados, a refletir sobre os impactos biopsicossociais e a importância em proporcionar melhor qualidade de vida à população nesse novo momento. Dados da última projeção da população efetuado pelo IBGE (2012) estima que no ano de 2060 a população idosa será maior que a população de jovem até 14 anos.

Diante dos dados estatísticos, estudos voltados para orientação na melhoria da qualidade de vida durante o envelhecimento têm sido relevantes (FRANÇA et al., 2019). Políticas nacionais e internacionais têm apresentado contribuições expressivas no cuidado do público idoso, formulando leis, ações e programas de promoção de saúde e prevenção de doenças, ajudando os profissionais que atuam com esse público no norteamento do processo de aposentadoria (MURTA et al., 2014).

Os Programas de Preparação para Aposentadoria (PPAs) surgiram nos Estados Unidos na década 50, começando o desenvolvimento no Brasil no final da década de 80 (COSTA et al., 2016). A princípio o programa apresentava breves informações a respeito da temática, atualmente foram incorporadas reflexões sobre a importância da qualidade de vida e os impactos permeados por esse momento de mudança, ajudando o indivíduo construir um novo projeto de enfrentamento levando em consideração sua subjetividade (PAZZIM; MARIN, 2016).

Desde que os PPAs foram implementados e legitimados no Brasil, os profissionais de psicologia, mesmo de forma incipiente, vêm desenvolvendo a implementação dos programas no meio das instituições, sejam elas públicas ou privadas, como foi possível evidenciar na pesquisa realizada por Boehs et al (2017) onde demonstra que desde a chegada do PPAs no Brasil até o ano de 2005 apenas 5 artigos foram publicados, aumentando esse número para 13 publicações no período de 2006 a 2010, ocorrendo no período de 2011 a 2016 
um aumento significativo de 24 artigos computáveis.

Diante dos dados, o presente artigo tem como objetivo descrever sobre os fatores biopsicossocial que influenciam de forma negativa o processo de aposentadoria e propor a implantação de um Programa de Preparação de Aposentadoria (PPA) no Corpo de Bombeiros Militar do Estado de Sergipe (CBMSE), denominado "Reformação", buscando contribuir para saúde biopsicossocial dos profissionais militares no processo de aposentadoria por meio de planejamento e orientação para nova fase da vida, auxiliando nessa transição de forma preventiva e promotora de bem-estar.

A proposta para implantação do projeto é desenvolver um programa num período de 4 meses, distribuídos em 4 etapas, realizados em encontros quinzenais, com duração de três horas, com os profissionais que estão no processo de aposentadoria. A estratégia envolve um trabalho de forma interdisciplinar utilizando técnicas de avaliação psicológica, aplicação de questionário, palestras informativas, dinâmicas vivenciais, debates, reflexões, depoimentos, proporcionando ao militar esclarecimento e reflexão sobre a nova fase da vida, orientando-o para o pós-carreira, ou "reserva/reforma", termos utilizados no contexto militar, ajudando-o enfrentar o processo com melhor qualidade de vida.

As etapas têm como finalidade trabalhar na divulgação do programa, efetuar o levantamento do perfil dos militares e suas expectativas por meio de questionário, promover debates e reflexão sobre as principais temáticas e, por fim, elaborar um planejamento de futuro, reorientando a enfrentar a nova fase. Pretende-se, após a divulgação da proposta de implementação do programa na instituição militar, conseguir adesão por parte dos gestores e efetivar a implantação no intuito de contribuir para saúde biopsicossocial dos militares, diminuir os sentimentos ambivalentes que surgem nessa fase, promover mudanças de comportamento na busca de melhor qualidade de vida dos reformados. 


\section{TRABALHO X IDENTIDADE DE QUEM FAZ A HISTÓRIA DO CORPO DE BOMBEIROS}

É culturalmente imposto como ditado popular que "O trabalho dignifica o homem". A frase revela o sentido subjetivo de valorização que o trabalho representa para o indivíduo. Mas, expor sobre o significado do trabalho não tem se revelado tarefa fácil, pois assume sentidos variados conforme o tempo, cultura, e contexto social que o indivíduo está inserido. Para Martins e Borges (2017) esse mesmo trabalho pode apresentar fatores que levem o indivíduo a experienciar um ambiente de prazer ou de sofrimento.

A própria etimologia da palavra trabalho tem um sentido doloroso, vem do latim tripalium, formado pela junção do tri, termo que significa três, e palum, significando madeira. Tripalium então passou a ser denominado instrumento de tortura constituído de três estacas de madeira afiadas.

Tripalium era um instrumento feito de três paus aguçados, algumas
vezes ainda munidos de pontas de ferro, no qual os agricultores
bateriam o trigo, as espigas de milho, o linho, para rasgá-los e
esfiapá-los. A maioria dos dicionários, contudo, registra tripalium
apenas como instrumento de tortura, o que teria sido originalmente,
ou se tornado depois. A tripalium se liga o verbo do latim vulgar
tripaliare, que significa justamente torturar (ALBORNOZ, 1998, p.10-
11).

As transformações oriundas do surgimento do capitalismo provocaram um sentido diferenciado do trabalho para o indivíduo, se comparado a períodos anteriores vivenciados em cada época e em diferentes sociedades. Desta forma, o trabalho passa a ter o fim de "propiciar a expansão da riqueza e do máximo lucro. Nessa perspectiva, o trabalho passa a ser considerado em função do capital e não mais das necessidades humanas" (LOUREIRO et al., 2013, p. 76).

Portanto, atualmente o termo trabalho envolve várias possibilidades de significados, levando em consideração a subjetividade de cada indivíduo de como ele concebe o serviço em determinada fase da vida, o que torna essa 
relação complexa. Há um sentido dicotômico, alguns momentos se revelando como uma relação prazerosa, gratificante, de realização, poder, independência e em outros momentos de fardo, desprazer, enfado. Logo, é notório o entendimento de que o exercício laboral constituído por várias e ambíguas imputações de significados e percepções (ZANELLI et al., 2008).

Considerando o sentido social, o trabalho assume um papel importante na vida do indivíduo, pois é por meio da sua carreira profissional que projetos de vida são idealizados, desafios inerentes à profissão são vencidos, relacionamentos são feitos, experiências que contribuem expressivamente na construção da identidade do indivíduo fornecendo um sentido à vida.

Enquanto humanos, desenvolvendo o processo de socialização, somos preparados em todo período de nossa vida ao trabalho, estabelecendo dessa forma a base que dá sentido a nossa existência. Por meio do trabalho, as pessoas passam a acreditar em seu potencial, se orgulham a cada conquista, estabelecem rituais em cada fase que experiência, desenvolvendo a construção da identidade (ZANELLI et al., 2010).

A construção da identidade decorre de um processo que depende de vários aspectos implicados com o indivíduo. Assim, as experiências de cada um no contexto social, e a forma que esse sujeito se sente como parte desse meio, e como é percebido pelo outro, devem ser considerados como fatores de identificação e formação do sujeito.

Nesse sentido, possuir uma identidade consiste em "constituir-se enquanto sujeito diferente do outro e reconhecido como tal" (SANTOS, 1990, p.19). É descobrir-se como integrante da sociedade, assumindo um lugar de poder a partir das interações no contexto social.

Logo, falar de identidade não está atrelado apenas à identificação pessoal tendo em vista que nossa identidade é construída levando em consideração os papéis sociais que desempenhamos durante toda vida, e suas relações interpessoais, bem como a valorização e o significado que a sociedade atribui àquele que trabalha (SOARES et al., 2010). São esses 
processos de percepção e autoconceito vivenciados pelo indivíduo que causam influências sobre a identidade profissional e pessoal.

Diante do exposto, a identidade militar apresenta um contexto singularizado, comparado a outros ambientes de trabalho. Pois, o grupo dos profissionais que formam a instituição, constituído e regido por regulamento que disciplinam sua conduta, além de possuir uma estrutura hierárquica que estabelece a relação de poder entre os pares, muitas vezes, essa identidade militar perpassa do ambiente profissional para o ambiente familiar.

Os militares, mesmo fora do ambiente profissional, agem conforme as regras, regulamentos, treinamentos e padronizações, no seu cotidiano (NATIVIDADE, 2009). Ao assumir esse papel diante da sociedade o sujeito organiza seu senso de pertencimento nas relações com o outro e elabora a construção de sua identidade pessoal (SANTOS, 1990).

Compreendendo a identidade é possível perceber a importância de preparar o indivíduo no enfrentamento do processo de aposentadoria, pois esse período pode ser vivenciado como sendo a perda de identidade. Não é um simples desvencilhar da atividade laboral, vários fatores relacionados com o mundo do sujeito devem ser levados em consideração, a fim de proporcionar melhor segurança e bem-estar na nova fase da vida.

\section{APOSENTADORIA: PRAZER OU DESPRAZER?}

A última projeção feita pelo IBGE (2012) aponta que em 2060 a população de idosos será de aproximadamente $25,5 \%$, enquanto a dos jovens até 14 anos será de $14,7 \%$. As informações da revisão ainda assinalam que a população do país deverá parar de crescer em 2047, caindo gradualmente nos anos seguintes.

Os dados revelam a importância em promover ações que possibilitem diminuir os impactos biopsicossociais no processo de envelhecimento. Para Antunes (2016) essas ações podem contribuir significativamente na qualidade 
de vida e bem-estar do indivíduo. Algumas ações são: a lei brasileira $\mathrm{n}^{0}$ $10.741 / 2003$ que trata do estatuto do idoso e outras legislações correspondentes norteiam ações voltadas a esse público, onde o artigo 28. mobiliza o poder público a promover programas que preparem os trabalhadores para a aposentadoria (Brasil, 2003). A lei 8.842/1994, que dispõe sobre a Política Nacional do Idoso, também aborda artigos específicos enfatizando a criação, estimulação e manutenção de programas de preparação para aposentadoria nos setores públicos e privados (BRASIL, 1994).

Apesar disso, o processo de aposentadoria gera em muitos indivíduos sentimentos de ambivalência, para alguns vem causando confusão em seu estado de humor, suscitando medo de perder a condição social, além de gerar ansiedade, provocando outras doenças de ordem psíquica (PAZZIM; MARIN, 2016). Enquanto outros experimentam a sensação de missão cumprida um momento oportuno da realização de projetos engavetados 0 momento adequado para vivenciar prazerosamente outra fase da vida (FRANÇA et al, 2013).

Essa ambivalência está intrinsecamente associada à maneira como o indivíduo se percebe, bem como o modo pelo qual produz sentido as suas experiências de vida, definindo sua postura diante da aposentadoria, que pode se apresentar de maneira prazerosa ou dolorosa. Podemos associar com a ambivalência "bem-estar" e "loucura" apresentada por Dejours quando fala sobre o trabalho "como o espaço de luta que ocorre o campo situado entre, de um lado, o bem-estar, e, de outro, a doença mental ou a loucura" (DEJOURS, 1993, p.153). Se envolvido pelo sentimento de desprazer, o indivíduo pode apresentar dificuldades em enfrentar as transformações pertinentes ao processo de aposentadoria.

Logo, essa passagem se apresenta de maneira diferenciada. Uns encaram a perda dos vínculos com amigos, à rotina que o trabalho proporcionou durante toda uma vida e enfrentam uma crise de identidade. Enquanto outros, não se importam aproveitando para dedicar-se a melhoria do 
seu bem-estar, cuidando da saúde, colocando seus projetos em prática, fazendo novas amizades (MURTA et al., 2014).

Enfrentar as perdas na aposentadoria torna-se ainda mais doloroso entre militares, mesmo que haja o desejo de liberdade, o indivíduo é tomado pelo desejo de continuar trabalhando recebendo os brios favorecidos pelos serviços prestados a sociedade, que o reconhece como verdadeiros heróis ou anjo da guarda, potencializando significativamente o prazer de manter-se na ativa, causando um sentimento confuso no momento de desvencilhar-se da instituição.

Em relação à aposentadoria do corpo de bombeiro militar, a lei ํo 9.717/1998 aborda as regras gerais de organização referente à previdência dos servidores públicos em geral incluindo os militares (Brasil, 1998). E, especificamente para os militares, a aposentadoria encontra uma sessão organizada na lei № 2066/1976 que versa sobre o Estatuto dos policiais militares de Sergipe (Sergipe, 1976).

A transição da aposentadoria além de envolver questões administrativas e jurídicas, muito bem organizados pelas leis e estatutos, provoca no indivíduo algumas transformações singulares que pode ser de ordem psíquica, social e biológica. A mudança, apesar de parecer simples, vai além do sentido burocrático na aplicabilidade dos direitos, transcorre o sentido subjetivo de não aceitação do fim de uma vida regada de rotinas regras e leis, gerando situação de desconforto e mal-estar, consequentemente complicações na vida do aposentado, que não enxerga o momento como possibilidade de viver outras experiências (ZANELLI, 2010).

\section{MÉTODO PROPOSTO}

A proposta de implantação de um Programa de Preparação para Aposentadoria - PPA no contexto militar, especificamente no Corpo de Bombeiros Militar de Sergipe, possibilitará uma reflexão sobre os fatores que 
influenciam de forma negativa no processo de aposentadoria, além de contribuir para saúde biopsicossocial auxiliando nessa transição de forma preventiva e promotora de bem-estar. O Programa tem como título sugestivo denominado "Reformação", aglutinação da palavra "Reforma", termo utilizado pelos militares que concluiu seu tempo de serviço na corporação, e a palavra "Ação", termo que indica movimento, atitude, disposição para agir diante de uma situação.

\subsection{Procedimentos de Implantação}

A implantação será apresentada em quatro etapas, prevista para ocorrer no período de seis meses, que proporcionará aos militares suportes necessários nessa fase da vida. As ações apresentadas dispõem de palestras, debates, aplicação de questionários, testes psicológicos, workshop, dinâmicas vivenciais.

A primeira etapa compreende o momento de identificação da realidade institucional, seguida da sensibilização e divulgação da proposta aos militares com o intuito de obter maior adesão ao programa.

Na segunda etapa ocorrerá a apresentação oficial do programa, visando o esclarecimento de objetivos, metodologia e benefícios proporcionados ao militar durante o processo, finalizando com o questionário que ajudará a equipe avaliar o perfil e a perspectiva que o grupo tem a respeito da aposentadoria.

A terceira etapa será o início do programa, que contará com equipe multidisciplinar, para abordar as temáticas mais significativas para ajudar 0 individuo ressignificar o momento da aposentadoria. A estruturação se dará em quatro módulos, cada módulo com dois encontros. Os temas mais abordados nos programas de preparação para aposentadoria são os relacionados aos aspectos jurídicos, questões relacionadas a previdência, aspectos financeiros, cuidados com a saúde física, mental e social, entre outros (FRANÇA et al., 2019). As palestras têm finalidade de levar o indivíduo a reflexão e percepções sobre o momento de mudança, além de promover informações pertinentes aos 
diversos aspectos que envolvem o programa, contribuindo, assim para a modificação de percepção negativa referente ao processo de "reforma".

Quando há uma preparação as transformações que ocorrem no processo de aposentadoria e seus impactos tendem a serem minimizados e crise de identidade e fatores psicológicos tende a não existir, dando lugar a novos planejamentos (SOARES, COSTA, 2011). E o tema planejamento tem recebido grande atenção para aposentadoria.

Nesse sentido alguns recursos como o apoio familiar, novos vínculos de amigos, prática de atividade física, busca de reeducação alimentar, trabalhos voluntários, tem demonstrado pontos positivos na diminuição dos impactos da crise no processo de aposentadoria (MURTA et al, 2014). Então, preparar o indivíduo no enfrentamento das problemáticas atreladas à aposentadoria, permitirá melhoria na qualidade de vida, além de proporcionar valorização da sua nova fase.

Quadro 1 - Estruturação dos módulos para implementação do Programa
Reformação \begin{tabular}{|r|r|}
\hline \multicolumn{2}{|c|}{ MÓDULO 1 - Tema: Os sentidos da vida } \\
\hline \multicolumn{2}{|c|}{ REFORMAÇO - (Programa de Preparação para Reforma/Aposentadoria) } \\
\hline $1^{\circ}$ Encontro & Direitos e deveres: aspectos legais da aposentadoria na previdência \\
\hline $2^{\circ}$ Encontro & O significado e sentimentos do trabalho e da aposentadoria \\
\hline \multicolumn{2}{|c|}{ MÓDULO 2 - Tema: Aspectos Jurídicos, Finanças e Previdência } \\
\hline $3^{\circ}$ Encontro & Direitos e deveres: aspectos legais da aposentaria na previdência \\
\hline $4^{\circ}$ Encontro & Organizando minhas finanças \\
\hline MÓDULO 3 - Tema: Qualidade de vida e bem-estar na reforma/aposentadoria \\
\hline $5^{\circ}$ Encontro & O sentido de si: uma reflexão do tempo livre \\
\hline
\end{tabular}




\begin{tabular}{|l|l|}
\hline $6^{\circ}$ Encontro & $\begin{array}{c}\text { Saúde e bem-estar } \\
\text { MÓDULO 4 - Tema: Meu projeto de futuro }\end{array}$ \\
\hline $7^{\circ}$ Encontro & Construindo um novo projeto de vida \\
\hline $8^{\circ}$ Encontro & Recomeçando o novo projeto \\
\hline
\end{tabular}

No módulo 1 os temas trabalhados têm o objetivo de promover a integração, contrato grupal e autoconhecimento dos militares no processo de aposentadoria, além de proporcionar reflexão sobre os diversos sentidos atribuídos ao trabalho e a reforma. No módulo 2 o foco principal é esclarecer a respeito dos aspectos Jurídicos, Finanças e Previdência, propiciando reflexões sobre como organizar a vida financeira após a aposentadoria. No módulo 3 será apresentado informações sobre ações importantes à saúde, que proporcionam ao indivíduo bem-estar e melhor qualidade de vida. Por fim o módulo 4 promoverá a elaboração de um projeto de futuro, possibilitando que ele enfrente com autonomia a nova etapa da vida, desmistificando a ideia negativa associada ao fim da vida.

A quarta etapa do processo, constitui um momento de confraternização de encerramento com aplicação de questionário para avaliação da percepção dos participantes sobre o desenvolvimento do projeto.

\section{RESULTADOS ESPERADOS E CONSIDERAÇÕES FINAIS}

Nem sempre a transição para a aposentadoria é vivenciada de forma positiva, há diversos fatores implicados e complexos que envolvem a construção de identidade que o individuo elaborou ao longo da vida que podem impactar de forma negativa sua qualidade de vida (MARTINS; BORGES, 2017). Trata-se de um processo vivenciado de maneira singular provocador de sentimentos ambivalentes e sua inobservância pode desencadear 
desequilíbrios aos envolvidos de forma direta ou indiretamente.

Tendo como premissa que o trabalho constitui o pilar da identidade do indivíduo (MARTINS; BORGES, 2017), para os militares, a mudança do espaço ativo, produtivo, operacional para uma situação de inativo, aposentado ou reformado, pode provocar uma crise existencial, entendendo que esse momento significa o fim da sua identidade militar, tão almejada, vivenciada e muitas das vezes ovacionada pela sociedade, dando descrédito ao sentido da vida longe da profissão.

Diante dos fatores que interferem negativamente 0 processo de aposentadoria pretende-se que após a implementação do programa, haja grandes contribuições na diminuição dos sentimentos ambivalentes que podem existir durante a nova fase da vida desses militares, provocando mudanças significativas de comportamento na busca de melhor qualidade de vida.

É fundamental que as organizações repensem novas ações que promovam valorização do indivíduo não apenas quando este estiver no serviço ativo, mas, no pós-carreira, possibilitando que as experiências adquiridas sejam úteis dentro e fora do contexto organizacional (FRANÇA et al., 2019).

\section{REFERÊNCIAS}

ALBORNOZ, Suzana. O que é trabalho. 5. ed. São Paulo: Brasiliense, 1998.

ANTUNES, M. H.; MORE, C. L. O. O. Aposentadoria, saúde do idoso e saúde do trabalhador: revisão integrativa da produção brasileira. Rev. Psicol., Organ. Trab., Brasília, v. 16, n. 3, p. 248-258, set. 2016. Disponível em $<$ http://pepsic.bvsalud.org/pdf/rpot/v16n3/v16n3a04.pdf>. Acesso em: 08 jul. 2021.

BOEHS, S.T. M. et al. Revisão da literatura latino-americana sobre aposentadoria e trabalho: perspectivas psicológicas. Rev. Psicol.,Organ. 
Trab., Brasília, v. 17, n. 1, p. 54-61, mar. 2017. Disponível em $<$ http://pepsic.bvsalud.org/scielo.php?script=sci arttext\&pid=S1984-

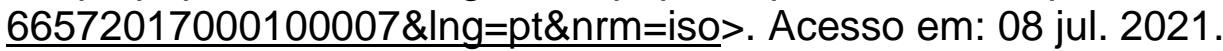

BRASIL. Estatuto do Idoso: lei federal № 10.741/03, de 1을 de outubro de 2003. Brasília, DF: Casa Civil Disponível em $<$ http://www.planalto.gov.br/ccivil 03/leis/2003/l10.741.htm>. Acesso em: 08 jul. 2021.

Política Nacional do Idoso: lei federal oㅡ 8.842, de 4 de janeiro de 1994. Brasília, DF: Presidência da República. Disponível em: <http://www.planalto.gov.br/ccivil 03/leis//8842.htm>. Acesso em: 08 jul. 2021.

. Regras gerais para a organização e o funcionamento dos regimes próprios de previdência social dos servidores públicos da União, dos Estados e do Distrito Federal e das outras providências: lei federal no 9.717/98, de 27 de novembro de 1998. Brasília, DF: Presidência da República. Disponível em: <http://www.planalto.gov.br/ccivil 03/leis/l9717.htm>. Acesso em: 08 jul 2021.

COSTA, A. M. M. R., et al. Preparação para a aposentadoria. In: COSTA, J. L. R., COSTA, A. M. M. R., and FUZARO JUNIOR, G., orgs. O que vamos fazer depois do trabalho? Reflexões sobre a preparação para aposentadoria [online]. São Paulo: Cultura Acadêmica, 2016, p. 33-43. Disponível em: < http://books.scielo.org/id/n8k9y/pdf/costa-9788579837630.pdf>. Acesso em: 08 de jul 2021.

DEJOUR, Christophe. Uma nova visão do sofrimento humano nas organizações. O indivíduo na organização: dimensões esquecidas. São Paulo: Atlas, 1993.

FRANCA, C. L. et al. Intervenção Breve na Preparação para Aposentadoria. Rev. bras. orientac. Prof, São Paulo, v. 14, n. 1, p. 99-110, jun. 2013. Disponível em: <http://pepsic.bvsalud.org/scielo.php?script=sci_arttext\&pid=S167933902013000100010\&lng=pt\&nrm=iso>. Acesso em 08 jul. 2021.

FRANÇA, L. H. F. P., et al. Análise dos Programas de Preparação para Aposentadoria (PPA) desenvolvidos por instituições públicas brasileiras. Revista Kairós: Gerontologia, v. 22, n. 1, p. 59-80, mar. 2019. ISSN 2176901X. em: $<$ https://revistas.pucsp.br/index.php/kairos/article/view/42941/28578>. Acesso 
em: 08 jul 2021.

IBGE. INSTITUTO BRASILEIRO DE GEOGRAFIA E estatístiCA. Censo Brasileiro de 2010. Rio de Janeiro: IBGE, 2012.

LOUREIRO, A. C. C. B., et. al. O sentido do trabalho humano. Psicologia do trabalho e Gestão de Recursos Humanos: estudos contemporâneos. 2. ed. São Paulo: Casa do Psicólogo, 2013.

MARTINS, L. F.; BORGES, E. S. Educação para aposentadoria: avaliação dos impactos de um programa para melhorar qualidade de vida pós-trabalho. Interações (Campo Grande), Campo Grande, v. 18, n. 3, p. 55-68, 2017. Disponível em: $<$ https://www.scielo.br/j/inter/a/nDn3gsz9WrnjL6bDVsH4ZHw/?lang=pt>. Acesso em: 08 jul 2021.

MURTA, S. G.; LEANDRO-FRANÇA, C.; SEIDL, J. Programas de educação para aposentadoria: Como planejar, implementar e avaliar. In. MURTA; S. G; LEANDRO-FRANÇA; C.; SEIDL, J. (Org.), Prevenção e Promoção da saúde mental, Políticas Públicas sobre envelhecimento ativo e educação para aposentadoria. Novo Hamburgo: Synopsis, 2014. p. $22-36$.

NATIVIDADE, M. R. Vidas em Risco: a identidade profissional dos bombeiros militares. Psicol. Soc., Florionópolis, v. 21, n. 3, p. 411-420, 2009. Disponível em:

$<$ https://www.scielo.br/j/psoc/a/g68zV4Q79txL4KhdpjBzGjR/abstract/?lang=pt $>$. Acesso em: 08 jul. 2021.

PAZZIM, T. A.; MARIN, A. Programas de Preparação para Aposentadoria: Revisão sistemática da literatura nacional. Rev. bras. orientaç. prof., Florionópolis, v.17, n. 1, p. 91-101, jun. 2016. Disponível em: $<$ http://pepsic.bvsalud.org/pdf/rbop/v17n1/10.pdf>. Acesso em: 08 jul. 2021.

SANTOS, Maria de Fátima Souza. Identidade e Aposentadoria. São Paulo: E.P.U., 1990.

SERGIPE, Estatuto dos Policiais Militares do Estado de Sergipe: lei estadual $\mathrm{n}^{\circ}$ 2066/76, de 23 de dezembro de 1976. Polícia Militar do Estado de Sergipe. Disponível em: <https://pm.se.gov.br/wp-content/uploads/2020/08/Estatuto-daPol\%C3\%Adcia-Militar-do-Estado-de-Sergipe-LEI-N\%C2\%BA-2.066-1976.pdf>. Acesso em: 08 jul. 2021.

SOARES, D. H. P.; COSTA, A. B. Aposentação: aposentadoria para ação. 
São Paulo: Vetor, 2011.

SOARES, D.H. P.; LUNA, I. N.; LIMA, M. B. F. A arte de aposentar-se: programa de preparação para aposentadoria com policiais federais. Estud. interdiscipl.envelhec., Porto Alegre, v. 15, n. 2, p. 293-313, 2010. Disponível em:<https://seer.ufrgs.br/RevEnvelhecer/article/view/12706/11482>. Acesso em: 09 jul. 2021.

ZANELLI, J. C.; BORGES-ANDRADE, J. E.; BASTOS, A. V. B. Psicologia, organizações e trabalho no Brasil. Porto Alegre: Artmed, 2008.

ZANELLI, J. C.; SILVA, N.; SOARES, D. H. P. Orientação para aposentadoria nas organizações de trabalho: construção de projetos para o pós-carreira. Porto Alegre: Artmed, 2010. 